\title{
Dexamethasone Implants in Patients with Naive Diabetic Macular Edema
}

\author{
Frédéric Matonti $^{\mathrm{a}-\mathrm{c}}$ Sébastien Guigou ${ }^{\mathrm{a}}$ Stephan Pommier ${ }^{\mathrm{a}} \quad$ Franck Meyer $^{\mathrm{a}}$ \\ Christian Hajjar $^{\mathrm{a}}$ Pierre-Yves Merite ${ }^{\mathrm{a}}$ Eric Parrat ${ }^{\mathrm{a}}$ Herve Rouhette $^{\mathrm{a}}$ Olivier Rebollo $^{\mathrm{a}}$ \\ Vincent Soler ${ }^{\mathrm{a}}$
}

ap1.5 Network, Mougins, and b Ophthalmology Department, Aix-Marseille Université, Hôpital Nord, and 'Institut de Neurosciences de la Timone (UMR7289), Aix-Marseille Université and CNRS, Marseille, France

\section{Dear Editor}

We have read the comments of Aknin et al. [1] on our article entitled 'Efficacy and safety of intravitreal dexamethasone implant in patients with diabetic macular edema' [2] with great interest. Aknin et al. [1] present a long-term follow-up study of patients with diabetic macular edema (DME) treated with Ozurdex ${ }^{\circledR}$. The authors report a significant improvement in the best corrected visual acuity, with a mean gain of at least 13 letters during the follow-up period and similar positive results on central retinal thickness. These results are better than those reported in our study [2] and many previous studies [3-5]. We think that these differences could be due to the baseline characteristics of the patient population, which could have influenced the investigation in the context of patient responses as well as of outcome measures. These findings suggest that some baseline characteristics of patients could affect the results obtained. Aknin et al. [1] enrolled $48 \%$ of treatment-naive patients, and $76 \%$ were naive to any previous antivascular endothelial growth factor injections. Likewise, Escobar-Barranco et al. [6] reported values significantly better in the naive group, while central retinal thickness decreased significantly and similarly in both groups (naive and non-naive patients).

Thus, these data support the notion that treatment-naive patients present better re- sponses with improved results compared to non-naive patients.

We can hypothesize that, as delaying DME treatment is highly pejorative on functional results $[7,8]$, delaying the most effective treatment is potentially just as deleterious (as delaying the introduced treatment). Furthermore, repeated laser treatment could generate some atrophic lesions and thus affect long-term functional results.

In conclusion, it seems necessary to identify and select, as early as possible, the most effective treatment for patients suffering from DME. We must also aim to correlate structural and functional criteria in order not to lose any valuable time without effective treatment: time is sight!

\section{References}

1 Aknin I, Melki L: Longitudinal study of sustained-release dexamethasone intravitreal implant in patients with diabetic macular edema. Ophthalmologica DOI: 10.1159/000446194.

-2 Guigou S, Pommier S, Meyer F, Hajjar C, Merite PY, Parrat E, Rouhette H, Rebollo O, Matonti F: Efficacy and safety of intravitreal dexamethasone implant in patients with diabetic macular edema. Ophthalmologica 2015;233:169-175.

-3 Boyer DS, Yoon YH, Belfort R Jr, Bandello F, Maturi RK, Augustin AJ, Li XY, Cui H, Hashad Y, Whitcup SM; Ozurdex MEAD Study Group: Three-year, randomized, sham-controlled trial of dexamethasone intravitreal implant in patients with diabetic macular edema. Ophthalmology 2014;121:1904-1914.
\4 Ozkaya A, Alagoz C, Alagoz N, Gunes H, Yilmaz I, Perente I, Yazici AT, Taskapili M: Dexamethasone implant in pseudophakic and nonglaucomatous subgroup of diabetic macular edema patients: a real life experience. Eur J Ophthalmol DOI: 10.5301/ ejo. 5000725 .

5 Augustin AJ, Kuppermann BD, Lanzetta P, Loewenstein A, Li XY, Cui H, Hashad Y, Whitcup SM; Ozurdex MEAD Study Group: Dexamethasone intravitreal implant in previously treated patients with diabetic macular edema: subgroup analysis of the MEAD study. BMC Ophthalmol 2015;15:150.

-6 Escobar-Barranco JJ, Pina-Marin B, Fernandez-Bonet M: Dexamethasone implants in patients with naive or refractory diffuse diabetic macular edema. Ophthalmologica 2015; 233:176-185.

7 Mastropasqua R, Toto L, Borrelli E, Di Antonio L, De Nicola C, Mastrocola A, Di Nicola M, Carpineto P: Morphology and function over a one-year follow-up period after intravitreal dexamethasone implant (Ozurdex) in patients with diabetic macular edema. PLoS One 2015;10:e145663.

8 Matonti F, Pommier S, Meyer F, Hajjar C, Merite PY, Parrat E, Rouhette H, Rebollo O, Guigou S: Long-term efficacy and safety of intravitreal dexamethasone implant for the treatment of diabetic macular edema. Eur J Ophthalmol DOI: 10.5301/ejo.5000787.

\section{KARGER}

E-Mail karger@karger.com

www.karger.com/oph
(C) 2016 S. Karger AG, Base

$0030-3755 / 16 / 2354-0244 \$ 39.50 / 0$
Dr. Frédéric Matonti

Ophthalmology Department, Aix-Marseille Université, Hôpital Nord Chemin des Bourrely

FR-13015 Marseille (France)

E-Mail frederic.matonti@ap-hm.fr 